\title{
Tribological behavior, mechanical properties and microstructure of Al-12Si-ZrC composite prepared by powder metallurgy
}

\author{
C.F. JOHN ${ }^{1 *}$, R.C. PAUL ${ }^{1}$, S.C.E. SINGH ${ }^{2}$, and T. RAMKUMAR ${ }^{2}$ \\ ${ }^{1}$ Department of Mechanical Engineering, CSI Institute of Technology, Thovalai 629302, Tamilnadu, India. \\ ${ }^{2}$ Department of Mechanical Engineering, Mepco Schlenk Engineering College, Sivakasi 626005, Tamilnadu, India.
}

\begin{abstract}
High-energy mechanical alloying method was used to prepare Al-12Si-xZrC ( $\mathrm{x}=0,5,10,15$ wt. \%) nanocomposites. Cylindrical preforms were prepared with an initial preform density of $89 \%$ by using a suitable die and punch assembly. The preforms were sintered in a muffle furnace with an inert gas atmosphere at a temperature of $550^{\circ} \mathrm{C}$, followed by cooling until room temperature has been attained. Scanning electron microscope (SEM) and X-ray diffraction (XRD) techniques were used to characterize the composites. Pin-on-disc wear testing machine was used to determine the tribological properties of the prepared composites. The results show that the wear loss reduced with increasing the reinforcement content and coefficient of friction increases gradually.
\end{abstract}

Key words: wear, friction, aluminium, silicon, zirconium carbide, powder metallurgy.

\section{Introduction}

Aluminium-based nanocomposites are being used for widespread applications in automotive and aerospace industries due to their best physical and mechanical properties. However, aluminium alloys are essential for lightweight, energy-efficient material applications owing to their low density. In the meantime, investigation has been focused on the production of aluminium metal matrix composites (MMCs) containing stiff particles, particularly for components with high wear and corrosion resistance [1]. In recent years, a lot of research is focused on aluminium matrix composites (AMCs). An optimal mixture of high strength and ductility gives aluminium matrix composites an extensive range of potential progressive applications [2-4]. The applications of aluminium alloys are limited because of poor wear resistance at room and elevated temperatures. It was reported by several researchers that the incorporation of hard ceramic particles such as $\mathrm{SiC}, \mathrm{Al}_{2} \mathrm{O}_{3}$, $\mathrm{TiC}, \mathrm{B}_{4} \mathrm{C}, \mathrm{TiB}_{2}$, and zirconium carbide $(\mathrm{ZrC})$ into aluminium alloys will enrich the wear resistance. These particles can be used in micron and nano scales [5]. Among these ceramic particles, nano-ZrC has a high modulus, enhanced hardness and high wear resistance. It is a very suitable material for producing aluminium matrix composites. The tribological and mechanical properties of aluminium metal matrix composites are influenced by many factors such as material type, size, weight content, and spatial dispersion of ceramic particles in the aluminium matrix composites. Al-12Si-xZrC nanocomposites are produced using three different techniques, i.e. solid state methods (mechanical alloying - MA, and powder metallurgy $-\mathrm{P} / \mathrm{M}$ ), molten methods (stir casting) and semi-solid methods.

*e-mail: fradyin@rediffmail.com
Normally, solid state methods are used to produce composites with high mechanical properties, because these methods deliver a uniform distribution of reinforcing phase particle in the matrix material [6-10]. Some trials were conducted to fabricate Al-12Si-xZrC nanocomposites using different techniques, but the mechanical alloying method is a suitable technique to fabricate Al-12Si-xZrC nanocomposites. No attempt has been made to fabricate $\mathrm{Al}$ matrix composites reinforced with $\mathrm{ZrC}$ particles using the $\mathrm{P} / \mathrm{M}$ method. In this present paper, an effort is made to study the outcome of wear behavior of Al-12Si-xZrC nanocomposites prepared with the mechanical alloying method. These composites were characterized using SEM and XRD. The wear behavior was calculated using the weight loss method. The worn surfaces and wear debris were characterized using SEM.

\section{Experimental procedure}

2.1. Materials. Aluminium and silicon with $99.5 \%$ purity and particle size of $44 \mu \mathrm{m}$ were purchased from Metal Powder Company Limited, Thirumangalam, Tamilnadu, India, and the $\mathrm{ZrC}$ powder with a high, 99.9\% purity and particle size of $400 \mathrm{~nm}$ was purchased from US Research Nanomaterials, Inc., USA. The individual powders were pulverized and mixed in a high-energy ball mill with ball-to-powder weight ratio of 20:1. The milling was done at a constant speed of $300 \mathrm{rpm}$ in a wet medium with a presence of toluene to avoid oxidation and agglomeration. Scanning electron microscope images were used for the analysis of mixed powder particles. Fig. 1 shows the received powders of aluminium, silicon, and zirconium carbide. From the SEM images, it can be visualized that aluminium was spherical in shape, silicon was flattened and nano-zirconium carbide had a cubic crystal shape. 
(a)

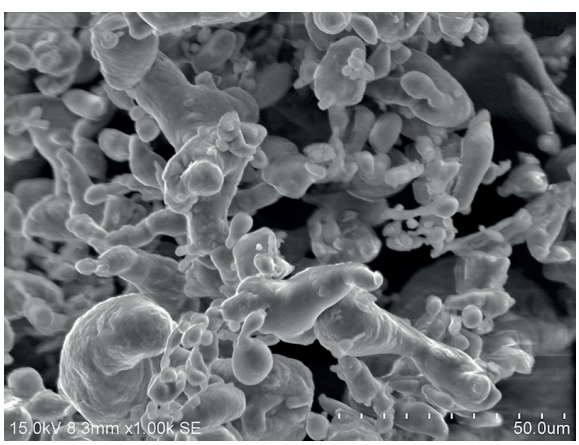

(b)

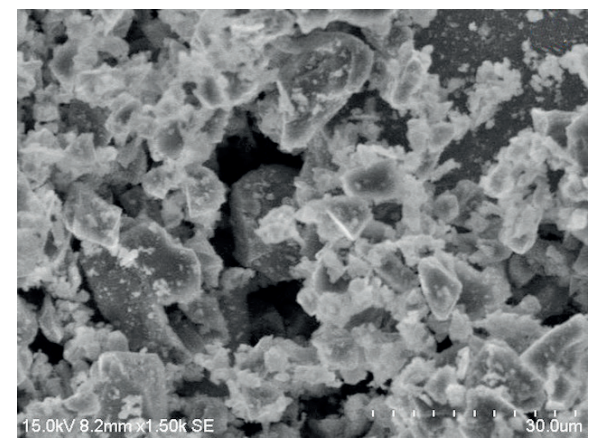

(c)

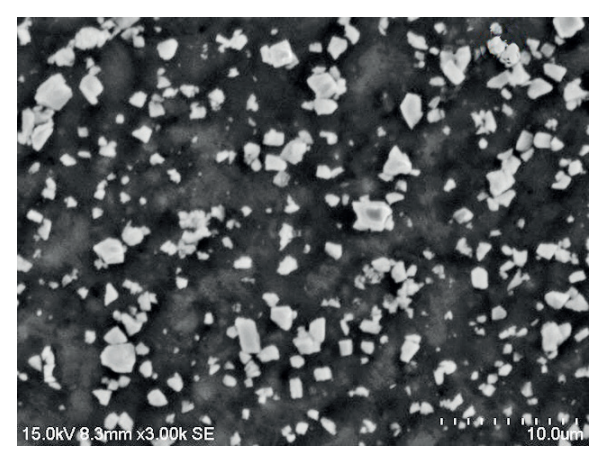

Fig. 1. SEM micrograph of received powders (a) aluminium, (b) silicon, and (c) zirconium carbide

2.2. Mechanical alloying of powders. Using the rule of mixtures, various weight percentages of Al-12-wt. $\% \mathrm{Si}-\mathrm{xZrC}(\mathrm{x}=0$, $5,10,15$ wt. \%) were deliberated. Mechanical alloying was carried out for the individual compositions using a ball mill with a tungsten carbide ampoule and balls of $5 \mathrm{~mm}$ radius in argon atmosphere. The ball-to-powder weight fraction was 20:1 and the duration of the composition alloying was $1 \mathrm{~h}$. To avoid oxidation and impurity of the MA processes, the process control agent was used in argon atmosphere. With the use of SEM micrograph it was confirmed that the $\mathrm{ZrC}$ nanoparticles were evenly distributed in all the Al-Si-xZrC nanocomposites. The SEM morphology also exposes that the sharp flattened structure of aluminium was fragmented, and because of that, the $\mathrm{ZrC}$ nano-particles have been incorporated with the Al-12Si alloy. To increase the strength of the soft aluminium material, different wt. \% of $\mathrm{ZrC}$ nanoparticles were reinforced into the matrix. It is clearly visible in the SEM micrographs in Fig. 2 (a-d).

It was noticed that all the particles were scattered homogenously through the sample. This is due to the usage of a ball mill for steady mingling of powders. The X-ray diffraction (XRD) exploration for the developed $\mathrm{Al}-12 \mathrm{Si}-\mathrm{xZrC}$ nanocomposite mixtures is shown in Fig. 3. These results specify the existence of $\mathrm{Al}$ as the major peaks; $\mathrm{Si}$ and $\mathrm{ZrC}$ were specified by minor peaks. The $\mathrm{ZrC}$ peak was clearly visible and can be identified in the $\mathrm{Al}-12 \mathrm{Si}-\mathrm{xZrC}$ nanocomposites. There is an indication for the increase in the intensity of the $\mathrm{ZrC}$ heights with the increase in wt. \% content of the Al-12Si-xZrC nanocomposites. A steady marginal shift of pure $\mathrm{Al}$ peaks to larger angles with an increase in the wt. $\%$ of the $\mathrm{ZrC}$ content was also observed. From Fig. 3, it can be inferred that there was no oxidation in the samples during the sintering process.
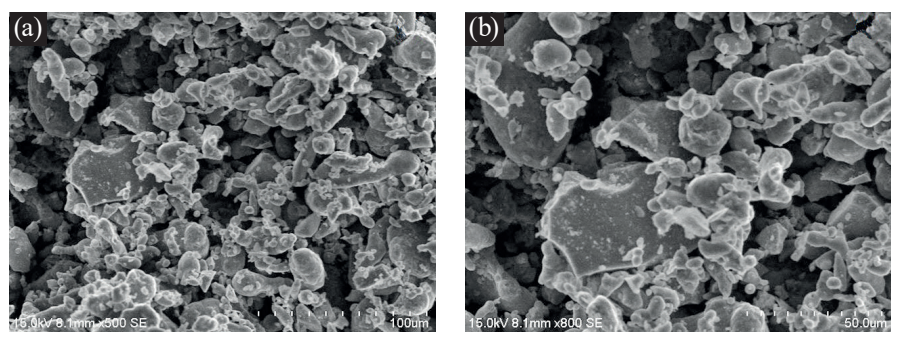

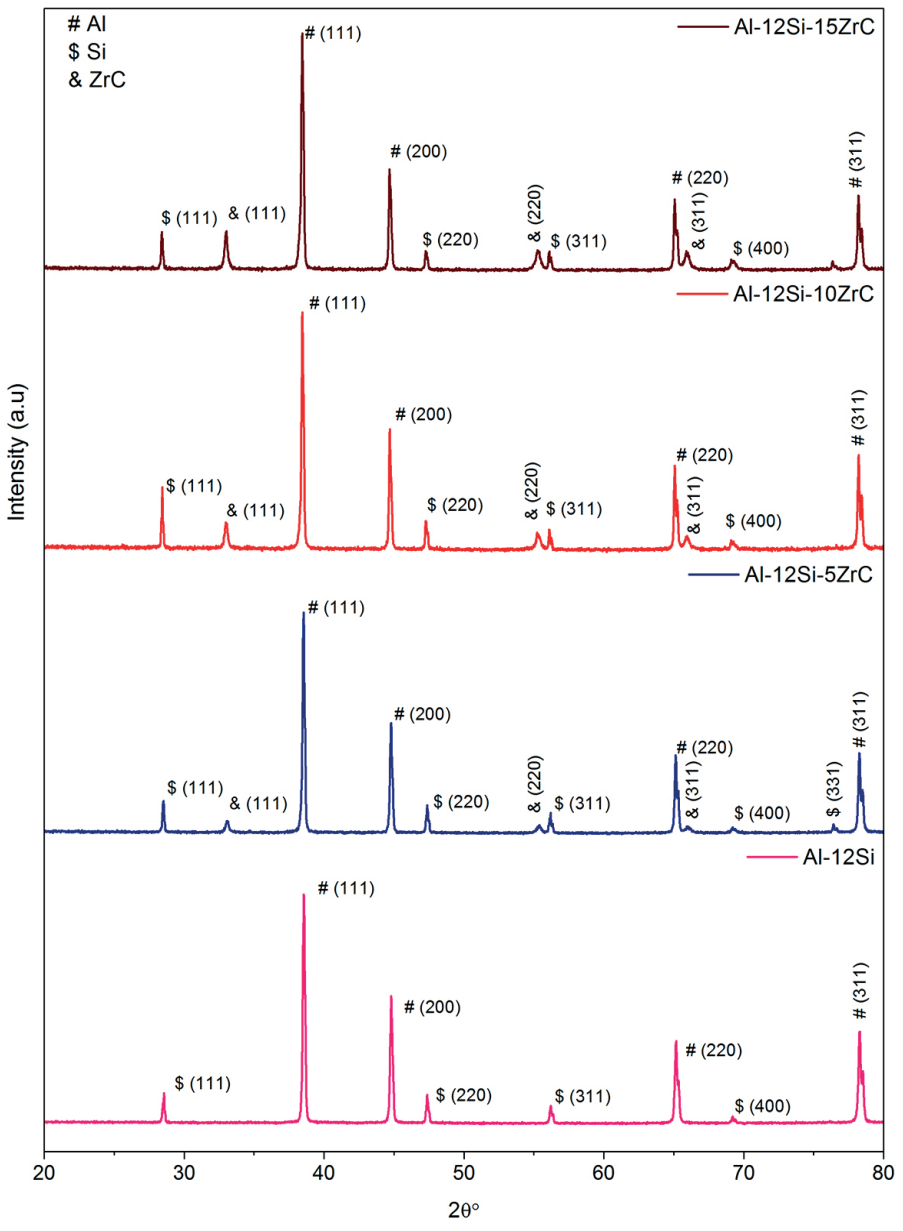

Fig. 3. XRD spectrum for various wt. \% of mixed powders, particles
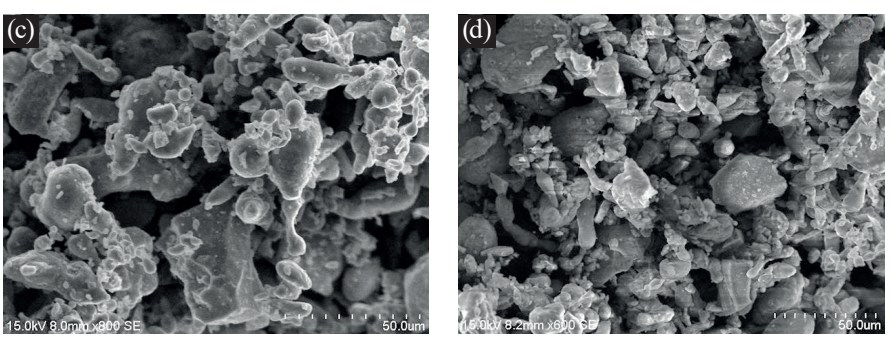

Fig. 2. SEM micrograph of the various wt. \% of powder after mixing (a) Al-12Si, (b) Al-12Si-5ZrC, (C) Al-12Si-10ZrC, and (d) Al-12Si-15ZrC 
2.3. Compaction and sintering. Cylindrical preforms of 10 $\mathrm{mm}$ in diameter and $25 \mathrm{~mm}$ in height were prepared in an appropriate die set assembly on a compression testing instrument with a $1000 \mathrm{kN}$ capacity. Compressing pressure was applied progressively, with 1.1 GPa for all samples [11]. Molybdenum disulphide was used to lubricate the die set assembly. Successively, the green preforms were immediately taken out from the die and kept in the inert gas muffle furnace for sintering. To prevent oxidation, the green preforms were sintered in the argon gas atmosphere at $550^{\circ} \mathrm{C}$, for a holding period of $1 \mathrm{~h}$. Subsequently, the preforms were cooled in the furnace itself until they reached room temperature. Furthermore, the sintered preforms were dressed with various emery papers. The Archimedes principle was used to measure the relative densities of the sintered preforms.

2.4. Density measurements. Determination of the experimental density for the sintered $\mathrm{Al}-12 \mathrm{Si}-\mathrm{xZrC}$ nanocompo- sites using the Archimedes principle was shown in Fig. 4. In Fig. 4 it is revealed that the experimental density of the sintered $\mathrm{Al}-12 \mathrm{Si}-\mathrm{xZrC}$ nano-composites was reduced due to the cluster of $\mathrm{ZrC}$ particles and pores existing in the green preform during

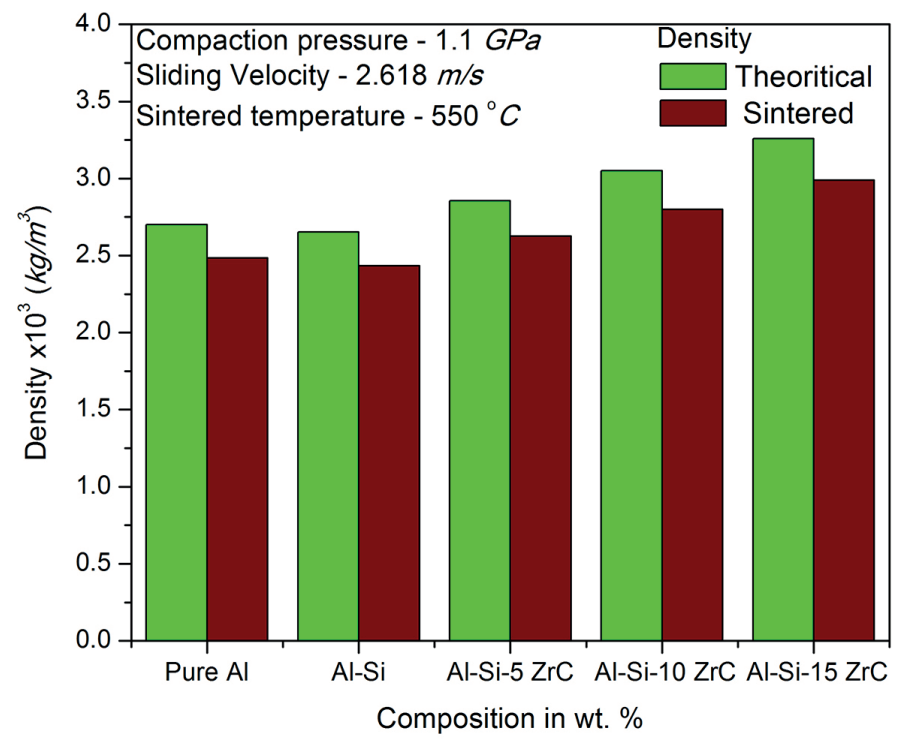

Fig. 4. Results of density measurements of composites at various wt. \% of $\mathrm{ZrC}$

compaction. The theoretical densities of the nanocomposite powder combinations were evaluated using the rule of mixtures, excluding the porosity. But the experimental density was calculated using the Archimedes principle for a sintered preform. The difference between the theoretical density and the experimental density shows the percentage of porosity present in the composites. Therefore, the density was different among theoretical and experimental values. The experimental density of Al-12Si-xZrC nanocomposites was increased. An electronic weight balance with an accuracy of $0.001 \mathrm{mg}$ was used to weigh the samples. Theoretical densities were measured for the
Al-12Si-xZrC nanocomposites for various compositions using the rule of mixtures [12]. The relative density after sintering was around $92 \%$ and it reveals that the porosity of the composites has reduced by up to $8 \%$. The wear resistance of the composites was reduced by maintaining the porosity level. Table 1 shows the compositions' theoretical density (TD) and experimental density (ED).

Table 1

Density of compositions

\begin{tabular}{|c|c|c|c|}
\hline Sl.No & Composition & TD $\left(\mathbf{k g} / \mathbf{m}^{\mathbf{3}}\right)$ & $\mathbf{E D}\left(\mathbf{k g} / \mathbf{m}^{\mathbf{3}}\right)$ \\
\hline 1. & $\mathrm{Al}$ & 2.7 & 2.484 \\
\hline 2. & $\mathrm{Al}-12 \mathrm{Si}$ & 2.651 & 2.434 \\
\hline 3. & $\mathrm{Al}-12 \mathrm{Si}-5 \mathrm{ZrC}$ & 2.856 & 2.625 \\
\hline 4. & $\mathrm{Al}-12 \mathrm{Si}-10 \mathrm{ZrC}$ & 3.05 & 2.799 \\
\hline 5. & $\mathrm{Al}-12 \mathrm{Si}-15 \mathrm{ZrC}$ & 3.259 & 2.988 \\
\hline
\end{tabular}

2.5. Wear test. The dry sliding wear tests of Al-12Si-xZrC nanocomposites were carried out using a pin-on-disc apparatus. The specimens were prepared as per the ASM, that is in G99-05 standard. The counter disc was made up of EN 31 steel hardened to 62 HRC. The specimens were cleaned with acetone before and after the wear tests. The specimens were weighed with an accuracy of $0.001 \mathrm{mg}$ to determine the weight loss based on formula (1). The frictional force was measured while conducting the experiment itself, and then the frictional force was converted into coefficient of friction based on (2).

$$
\begin{gathered}
\mathrm{W}=\mathrm{W}_{1}-\mathrm{W}_{2}, \\
\mu=\mathrm{F} / \mathrm{P},
\end{gathered}
$$

where $\mathrm{W}$ is weight loss; $\mathrm{W}_{1}$ and $\mathrm{W}_{2}$ are the weight of the specimen before and after the wear test, respectively; $\mu$ is coefficient of friction, $\mathrm{F}$ - frictional force, and $\mathrm{P}$ - applied load.

\section{Results and discussion}

3.1. XRD analysis. Figure 3 shows the XRD pattern of the Al-Si composite reinforced with different wt. \% of $\mathrm{ZrC}$ particles. Al, Si, and $\mathrm{ZrC}$ peaks were indexed using JCPDS files (file numbers 851327, 800018, and 730477, respectively). Fig. 3a shows the peak of Al-Si composite powders, where the highest peak indicates the presence of $\mathrm{Al}$ and the lowest peak indicates the presence of Si. Fig. 3 (b-d) shows the presence of different wt. $\%$ of $\mathrm{ZrC}$ particles present in the composite powders, and it also consist of predominantly $\mathrm{Al}$ and $\mathrm{Si}$ peaks because of $\mathrm{ZrC}$ wt. \% being smaller compared to the other particles. Furthermore, the XRD peak intensities of $\mathrm{ZrC}$ phase have increased noticeably with an increase of wt. $\%$ of $\mathrm{ZrC}$, and there are no oxide peaks to be observed in the XRD analysis of Al-Si-xZrC composites [13]. 


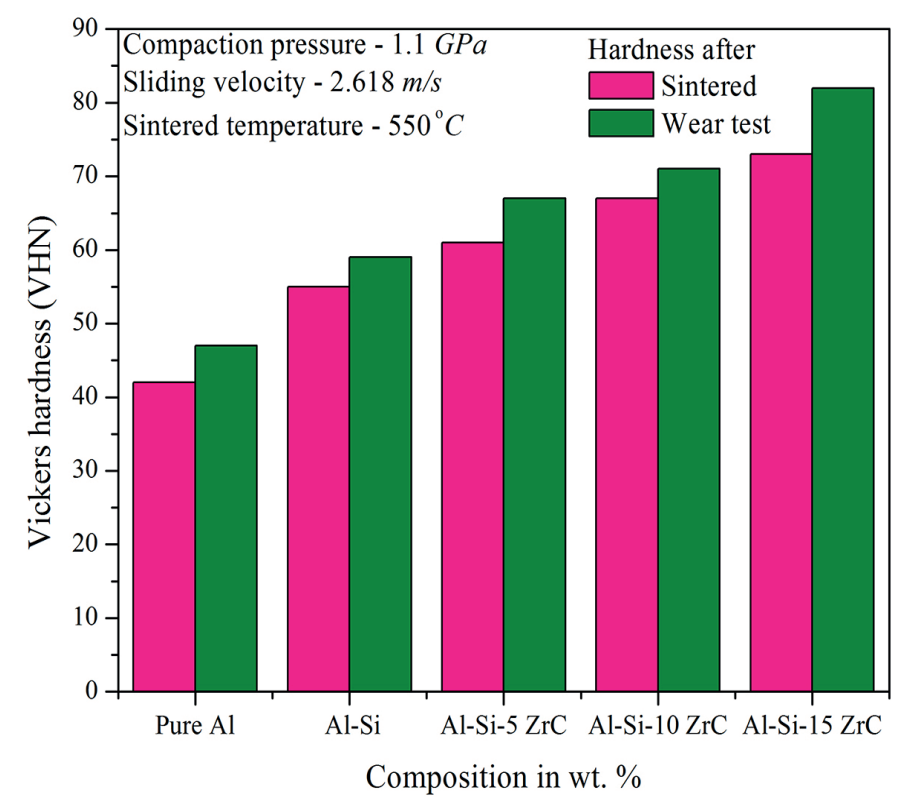

Fig. 5. Vickers hardness of composites at various wt. \% of $\mathrm{ZrC}$

3.2. Hardness measurements. The hardness test was performed using a Vickers hardness testing machine under a load of 490.5 $\mathrm{N}$ with a diamond indenter for a duration of $30 \mathrm{~s}$. Before testing, the specimens were polished with various emery papers. The measurements were taken at five different places on each sample to find the average value of hardness in order to achieve the desired accuracy of the measurements. Figure 5 reveals the increase of hardness of the Al-12Si-xZrC nanocomposites with an increase in $\mathrm{ZrC}$ nanoparticles, compared to pure aluminium. This shows that there has been a continuous increase in the hardness due to the presence of hard asperities. After the wear tests, the specimens were polished and the indentation process was repeated. Hardness has improved progressively after the wear test [14]. Consequently, heat was generated at the bottom of the pin for varying loads, sliding distances, and sliding velocities. Thermal aging occured through the loading of the pin bottom and its contact with the counterface. Figure 5 shows the assessment of hardness of the specimens with different wt. \% of $\mathrm{ZrC}$ nano content. Figure 5 shows clearly that the hardness of a specimen increases due to the addition of $\mathrm{ZrC}$ nanoparticles into the $\mathrm{Al}-12 \mathrm{Si}-\mathrm{xZrC}$ nanocomposites.

Effect of load on the coefficient of friction. From Fig. 6(a-c), it is observed that the coefficient of friction increases with load, and a similar tendency was observed for all the composites. Furthermore, the friction coefficient is much higher due to fluctuation. A somewhat lesser coefficient of friction in the Al-12Si-xZrC nanocomposites may be attributed to the presence of extra carbide in the composite surface as well as in the removal layer. The $\mathrm{ZrC}$ nanoparticles containing composites show a comparatively inferior coefficient of friction compared to the base matrix [7]. Moreover, frictional heat was produced after the contact surfaces of pin and disc were in relative motion to each other. Since there was no time for heat dissipation, and due to continuous motion between the pin and disc surfaces, the carbon-rich layer enhanced the coefficient of friction. Consequently, the hard asperities
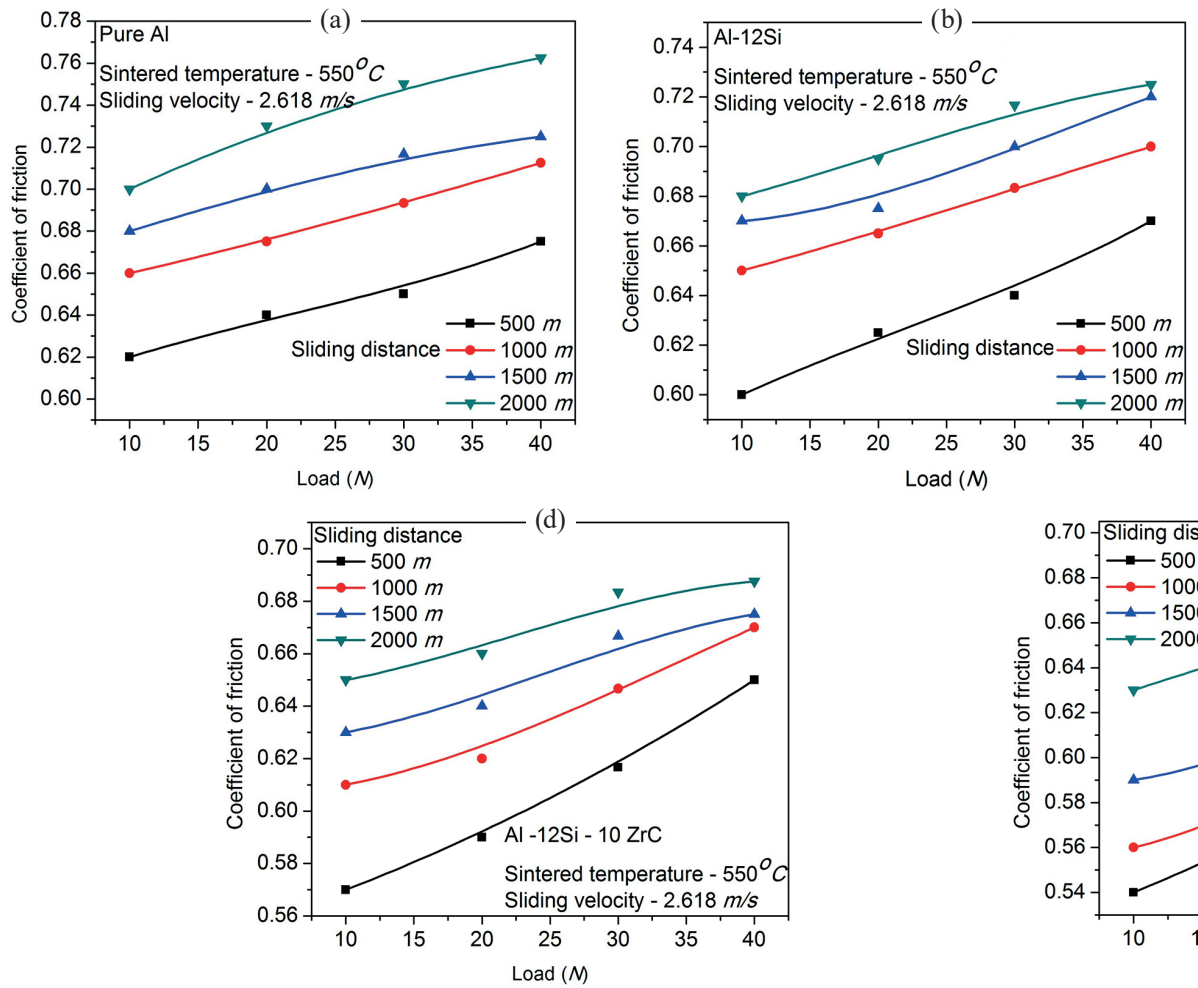

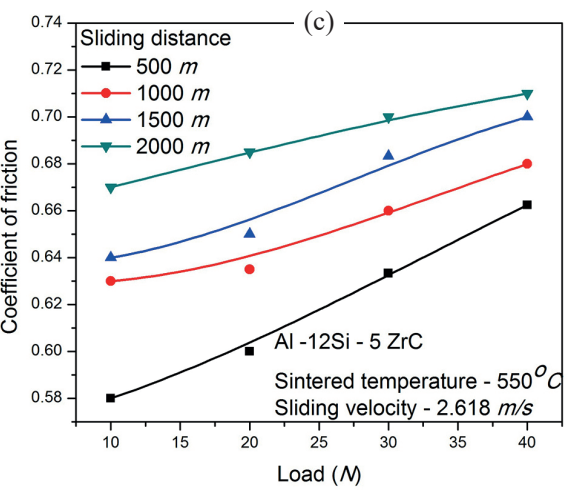

(e)

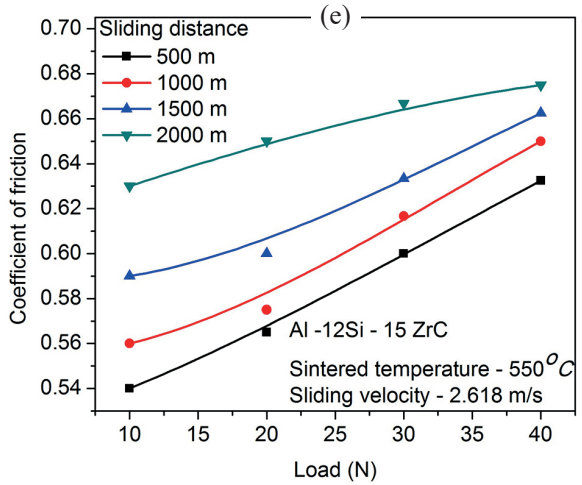

Fig. 6. Cofficient of friction as a function of load: (a) Al, (b) Al-12Si, (c) Al-12Si-5ZrC, (d) Al-12Si-10ZrC, and (e) Al-12Si-15ZrC 

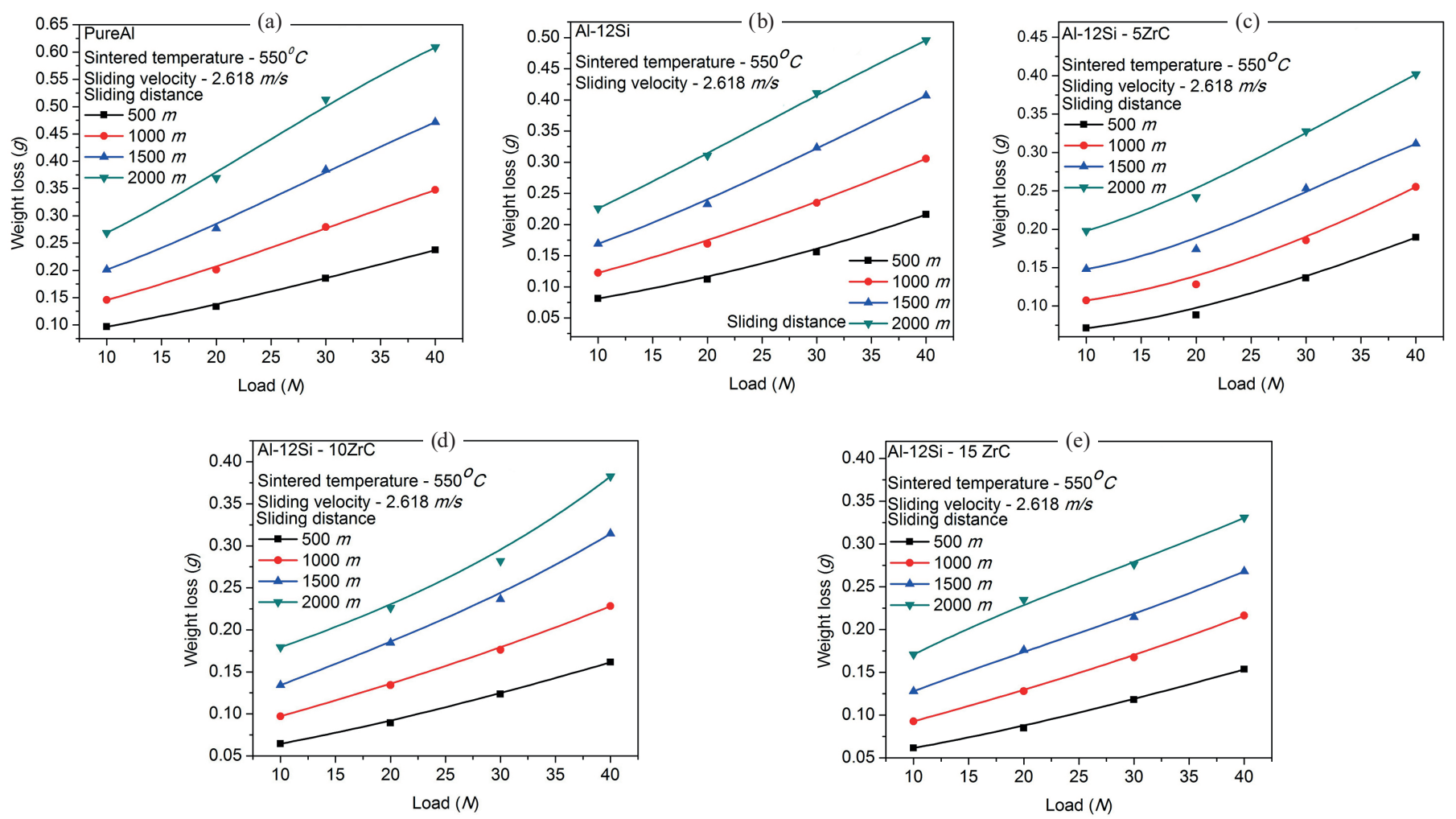

Fig. 7. Weight loss as a function of load: (a) Al, (b) Al-12Si, (c) Al-12Si-5ZrC, (d) Al-12Si-10ZrC, and (e) Al-12Si-15ZrC

of the composites and the coefficient of friction of the $\mathrm{ZrC}$ nanoparticle-included matrix were reduced compared to pure Al. These aspects help in providing higher control over the coefficient of friction in the Al-12Si-xZrC nanocomposites [15]. For all the Al-12Si-xZrC nanocomposite samples the coefficient of friction increased with an increase in load and sliding distance [12-14].

3.3. Effect of load on weight loss. Figure 7 shows the weight loss as a function of load and sliding distance. While increasing the applied load, the composition weight loss was also gradually increasing. The increase in weight loss was due to the friction created between the specimens and the counterface. Also, weight losses were reduced due to an increase in hardness of the Al-12Si-xZrC nanocomposites. This is due to the addition of a secondary $\mathrm{ZrC}$ particle, strengthening the soft Al matrix. Figure 7 shows that the wt. \% of $\mathrm{ZrC}$ content mostly influences the wear behavior of the composites. Initially, the weight loss was increasing linearly for all the sliding distances against the load at the initial stage, and then it was increasing exponentially due to an increase in the applied load and sliding distance, the nature of self-lubrication at the contact surface, and relative densification of Al-12Si-xZrC nanocomposites. It was found that pure aluminium experiences an enormously higher weight loss than Al-12Si-xZrC nanocomposites [18]. The contact surface was minimal and the asperities were piercing, solid, and stiff. Self-lubrication was exaggerated mostly by volume content, spatial distribution, and the size of $\mathrm{ZrC}$ nanoparticles. The increase in applied load increases the metal-to-metal contact and the wt. \% of $\mathrm{ZrC}$, and it causes inadequate formation of a carbon-rich layer at the contact zone. Subsequently, the surface of the composite pin will tend to plough due to the rigid asperities of the counterface material with an increase in normal load and increase of weight loss of composites. The coarse mating between the tribo-couple was reduced due to the presence of $\mathrm{ZrC}$ nanoparticles, which decrease the plastic deformation of the composite samples. It is realistic that the matrix can form a reinforcement layer on the surface as well, due to the similar wear constraints and conditions on Al-12Si$\mathrm{xZrC}$ nanocomposites. Furthermore, it is assumed that higher wear speed may lead to formation of a carbon-rich layer on the surface of the Al-12Si-xZrC nanocomposites. Concluding from the above discussion, the reinforcement content tends to decrease the weight loss. However, the weight loss marginally increases with an increase in applied load, sliding distance and high sliding velocity. Similar results have also been reported by researchers with regard to $\mathrm{SiC}, \mathrm{Al}_{2} \mathrm{O}_{3}$, and $\mathrm{TiB}_{2 .}$ [15-17].

\section{Conclusions}

In the present study, $\mathrm{Al}-12 \mathrm{Si}-\mathrm{ZrC}$ composites were fabricated by mixing aluminium, silicon and various weight percentages of $\mathrm{ZrC}$ nanoparticles by mechanical alloying, followed by the cold compaction method. The following conclusions were drawn from the study: 
- The hardness of the Al-12Si-xZrC nanocomposites was found to increase with an increasing $\mathrm{ZrC}$ content reinforcement into the Al-12Si matrix.

- The experimental density of the Al-12Si-xZrC nanocomposites was found to be lower compared to the theoretical density. This was due to the porosity content present in the sintered preform.

- XRD analysis of the composite powders shows presence of $\mathrm{Al}, \mathrm{Si}$ and $\mathrm{ZrC}$ phases without any other impurities.

- The weight loss decreased with an increase in $\mathrm{ZrC}$ nanoparticle reinforcement into the composite matrix, and also the weight loss of the nanocomposites increased linearly with increasing applied load and sliding distance.

- The friction co-efficient increased with increasing applied load and sliding distance. However, the $\mathrm{ZrC}$-containing composites indicate a lower friction coefficient than pure Al. This may be due to the increase in reinforcement content into the composite matrix.

\section{REFERENCES}

[1] R. Harichandran and N. Selvakumar, "Effect of nano/micro $\mathrm{B}_{4} \mathrm{C}$ particles on the mechanical properties of aluminium metal matrix composites fabricated by ultrasonic cavitation-assisted solidification process", Archives of Civil and Mechanical Engineering 16 (1), 147-158 (2016).

[2] M.M.H. Bastwrosa, A.M.K. Esawi, and A. Wifi, "Friction and wear behavior of Al-CNT composites", Wear 307 (1-2), 164-173 (2013).

[3] Y. Wang, W.M. Rainforth, H. Jones, and M. Lieblich, "Dry wear behaviour and its relation to microstructure of novel $6092 \mathrm{alu}-$ minium alloy- $\mathrm{Ni}_{3} \mathrm{Al}$ powder metallurgy composite", Wear 251 (1-12), 1421-1432 (2001).

[4] A. Abdollahi, A. Alizadeh, and H.R. Baharvandi, "Dry sliding tribological behavior and mechanical properties of A12024-5 wt. $\% \mathrm{~B}_{4} \mathrm{C}$ nanocomposites produced by mechanical milling and hot extrusion", Materials and Design 55, 471-481(2014).

[5] J. Corrochano, J.C. Walker, M. Lieblich, J. Ibáñez, and W.M. Rainforth, "Dry sliding wear behaviour of powder metallurgy $\mathrm{Al}-\mathrm{Mg}-\mathrm{Si}$ alloy- $\mathrm{MoS}_{2}$ composites and the relationship with the microstructure", Wear 270 (9-10), 658-665 (2011).

[6] M. Lieblich, J. Corrochano, J. Ibáñez, V. Vadillo, J.C. Walker, and W.M. Rainforth, "Subsurface modifications in powder metallurgy aluminium alloy composites reinforced with intermetallic $\mathrm{MoS}_{2}$ particles under dry sliding wear", Wear 309 (1-2), 126-133 (2014).
[7] D. Jun, L. Yao-hui, Y. Si-rong and Li Wen-fang, "Dry sliding friction and wear properties of $\mathrm{Al}_{2} \mathrm{O}_{3}$ and carbon short fibres reinforced Al-12Si alloy hybrid composites", Wear 257 (9-10), 930-940 (2004).

[8] H. Ahlatci, T. Kocer, E. Candan, and H. Cimenoglu, "Wear behaviour of $\mathrm{Al} /\left(\mathrm{Al}_{2} \mathrm{O}_{3 \mathrm{p}}+\mathrm{SiC}_{\mathrm{p}}\right)$ hybrid composites", Tribology International 39 (3), 213-220 (2006).

[9] G. Abouelmagd, "Hot deformation and wear resistance of P/M aluminium metal matrix composites", Journal of Materials Processing Technology 155-156, 1395-1401 (2004).

[10] T. Rajmohan, K. Palanikumar, and S. Arumugam, "Synthesis and characterization of sintered hybrid aluminium matrix composites reinforced with nano copper oxide particles and micro silicon carbide particles", Composites: Part B 59, $43-49$ (2014).

[11] N. Selvakumar and S.C.E. Singh, "Influence of nano $\mathrm{ZrC}$ content on tribological analysis, microstructure and mechanical properties of $\mathrm{Cu}-4 \mathrm{Cr}$ matrix composites produced by hot extrusion", Archives of Civil and Mechanical Engineering 16 (3), 537-552 (2016).

[12] K. Naplocha and K. Granat, "Dry sliding wear of A1/Saffil/C hybrid metal matrix composites", Wear 265 (11-12), 1734-1740 (2008).

[13] S.C.E. Singh and N. Selvakumar, "Effect of milled $B_{4}$ C nanoparticles on tribological analysis, microstructure and mechanical properties of $\mathrm{Cu}-4 \mathrm{Cr}$ matrix produced by hot extrusion", Archives of Civil and Mechanical Engineering, 17 (2), 446-456 (2017).

[14] S. Suresh and B.K. Sridhara, "Wear characteristics of hybrid aluminium matrix composites reinforced with graphite and silicon carbide particulates", Composites Science and Technology 70 (11), 1652-1659 (2010).

[15] S. Soleymani, A. Abdollah-zadeh, and S.A. Alidokht, "Microstructural and tribological properties of Al 5083-based surface hybrid composite produced by friction stir processing", Wear 278-279, 41-47 (2012).

[16] A. Devaraju, A. Kumar, A. Kumaraswamy, and B. Kotiveerachari, "Influence of reinforcements $\left(\mathrm{SiC}\right.$ and $\left.\mathrm{Al}_{2} \mathrm{O}_{3}\right)$ and rotational speed on wear and mechanical properties of aluminium alloy 6061-T6 based surface hybrid composites produced via friction stir processing”, Materials and Design 51, 331-341 (2013).

[17] Y.Q. Wang, A.M. Afsar, J.H. Jang, K.S. Han, and J.I. Song, "Room temperature dry and lubricant wear behaviors of $\mathrm{Al}_{2} \mathrm{O}_{3}$ / $\mathrm{SiC}_{\mathrm{p}} / \mathrm{Al}$ hybrid metal matrix composites", Wear 268 (7-8), 863-870 (2010).

[18] N. Selvakumar and T. Ramkumar, "Effects of high temperature wear behaviour of sintered Ti-6Al-4V reinforced with nano $\mathrm{B}_{4} \mathrm{C}$ particle", Transactions of the Indian Institute of Metals 69 (6), 1267-1276 (2016). 